\title{
Analysis of Visual Outcomes and Complications Following Levator Resection for Unilateral Congenital Blepharoptosis without Strabismus
}

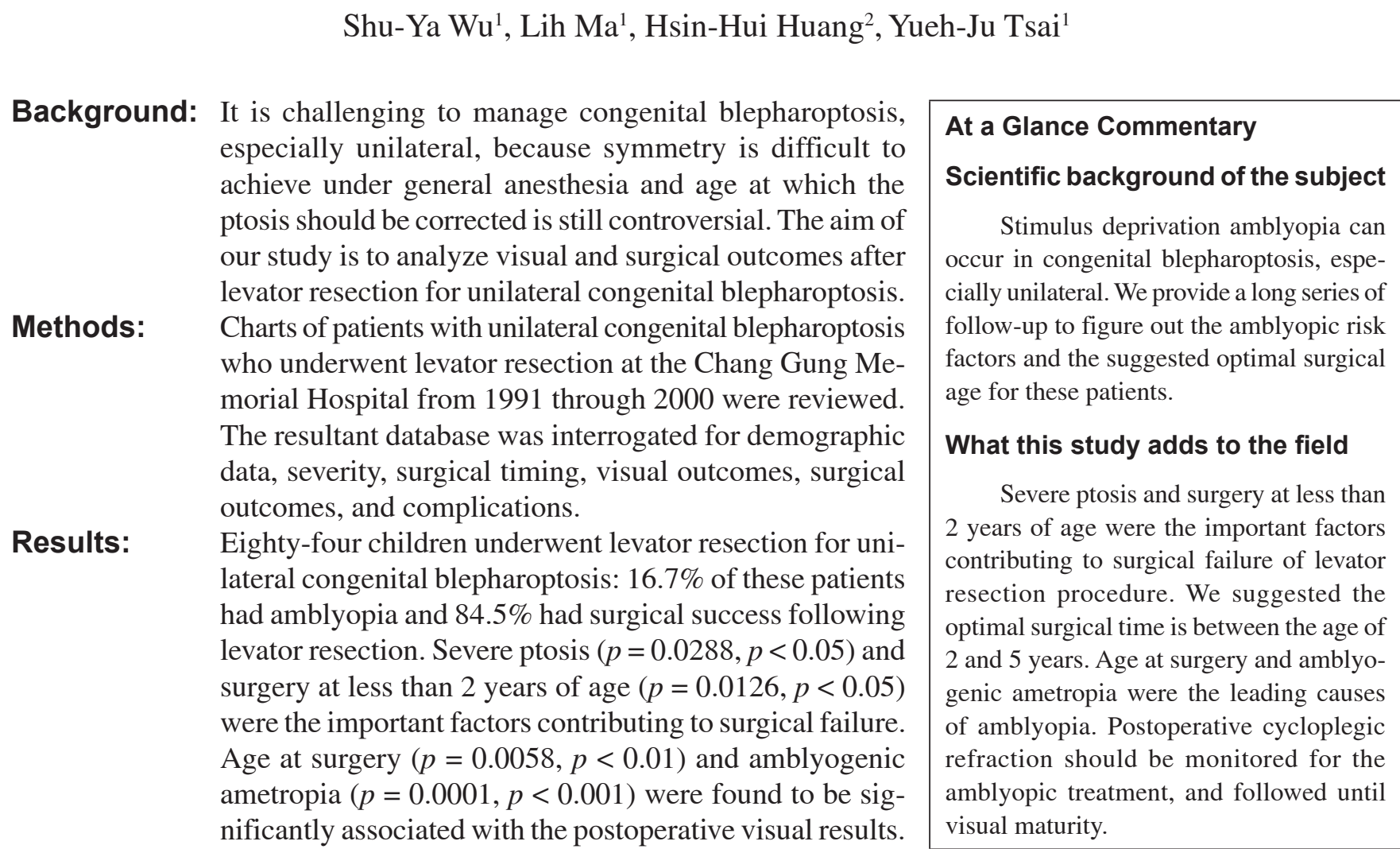

Conclusion: The levator resection provides satisfactory results both in function and cosmesis in patients with unilateral congenital blepharoptosis. Amblyogenic ametropia is the leading cause of amblyopia in the patients with unilateral isolated congenital blepharoptosis. However, patients with unilateral congenital blepharoptosis should have cycloplegic refraction as early as possible, and their visual status monitored until visual maturity.

(Biomed J 2013;36:179-187)

Keywords: amblyopia, levator resection, unilateral congenital blepharoptosis

$\mathrm{C}$ ongenital blepharoptosis is an embryological abnormality in the levator complex development that causes a lack of differentiation of the levator muscle and malposition of the eyelid. It is now well known that stimulus deprivation amblyopia can occur in congenital blepharoptosis, especially unilateral, ${ }^{[1-4]}$ and previous

From the ${ }^{1}$ Division of Orbital and Oculoplastic Surgery, Department of Ophthalmology, Chang Gung Memorial Hospital at Linkou, Chang Gung University College of Medicine, Taoyuan, Taiwan; ${ }^{2}$ Division of Hematology and Oncology, Department of Internal Medicine, China Medical University Hospital, Taichung, Taiwan

Received: Jun. 05, 2012; Accepted: Aug. 30, 2012

Correspondence to: Dr. Yueh-Ju Tsai, Division of Orbital and Oculoplastic Surgery, Department of Ophthalmology, Chang Gung Memorial Hospital at Linkou. 5, Fusing St., Gueishan, Taoyuan 333, Taiwan (R.O.C.). Tel: 886-3-3281200, ext. 8666; Fax: 886-3-3287798; E-mail: erinyjtsai@gmail.com

DOI: $10.4103 / 2319-4170.113854$ 
studies have indicated a high incidence of coexistent strabismus, amisometropia, and ametropia in children with congenital blepharoptosis. ${ }^{[1-6]}$ Therefore, it is an accepted practice to perform surgical correction for patients with occlusive blepharoptosis to aid in the management of amblyopia. ${ }^{[1-8]}$

Several different types of surgical procedure are used for correction of blepharoptosis ${ }^{[9]}$ The surgical approach chosen generally depends on the amount of levator function. ${ }^{[9-14]}$ When levator function is poor or absent, frontalis suspension remains the preferred surgical procedure for correction of congenital blepharoptosis. ${ }^{[9-13]}$ However, Epstein, ${ }^{[15]}$ Mauriello, ${ }^{[16]}$ and Anderson ${ }^{[17]}$ successfully performed maximal levator resection for poor levator function. In 1986, Blomgren also reported that anterior levator resection can be used all types of congenital ptosis and even in cases of poor levator function. ${ }^{[18]}$ In addition, correction of congenital blepharoptosis should be considered not only to improve function (visual results) but also for cosmetic appearance (symmetric eyelid contour and height). Levator resection is more anatomic and physiologic than frontalis suspension, without activation of the frontalis muscle to achieve satisfactory eyelid height, and with no brow scar.

Severely unilateral congenital ptosis is more challenging than bilateral ptosis because symmetry is difficult to achieve under general anesthesia and, ${ }^{[19-21]}$ at the age at which the ptosis should be corrected, is more controversial. Some surgeons advocate very early correction for patients with unilateral congenital ptosis to prevent amblyopia. ${ }^{[22,23]}$ Others prefer delaying ptosis surgery until the child is 4 years old. ${ }^{[24]}$ Because of these factors, the aim of this study was to retrospectively evaluate the visual outcomes and complications of levator resection in patients with unilateral congenital blepharoptosis and determine the optimal time for surgical correction of unilateral congenital blepharoptosis.

\section{METHODS}

This paper reports the results of a retrospective study of a series of interventional cases. Medical records of all the patients who underwent levator resection under general anesthesia before 8 years of age for isolated unilateral congenital blepharoptosis, which was performed by the same surgeon (Dr. Lih Ma) at Chang Gung Memorial Hospital between 1 June 1991 and 31 October 2000 were reviewed. However, patients with strabismus or a history of any previous surgery were excluded. This study complied with the policies of the institutional review board of this institution, and permission was granted to conduct the study.

Data were recorded on the gender, laterality of the operated eye, severity of ptosis, the age at which surgery was done, postoperative best-corrected visual acuity, post- operative refractive errors, and complications. The severity of ptosis was classified as mild, moderate, or severe, based on the criteria described by Freuh. ${ }^{[25]}$ In unilateral cases, the amount of ptosis was calculated as the difference in millimeters between the heights of the palpebral apertures: Mild ptosis was defined as $2 \mathrm{~mm}$ or less, moderate ptosis as 2-4 $\mathrm{mm}$, and severe ptosis as $4 \mathrm{~mm}$ or more - lower than the fellow upper eyelid level. Regardless of the grades of the levator muscle function, all the patients received levator resection.

Visual acuities were determined using the Snellen chart and refractions were measured a way with cycloplegia. Amblyopia was diagnosed as best-corrected visual acuity of 0.7 or less. Anisometropia was defined as a spherical difference of greater than 1.25 diopters or an astigmatism difference of greater than 1 diopter of cylinder between the two eyes. Amblyogenic ametropia was defined as high astigmatism of more than 2.5 diopters of cylinder, high hyperopia of more than 4.5 diopters, and high myopia of more than 3.0 diopters. All refractions were expressed as minus cylinder notation for comparison. The visual acuities and refractive errors of fellow eyes were used as age-matched controls.

The surgical outcome for ptosis was judged as good, fair, or poor, based on the criteria described by Berry-Brincat and Willshat. ${ }^{[26]}$ Good surgical outcome was defined as single operation and good cosmesis (residual ptosis less than or equal to $1 \mathrm{~mm}$ ) without any complications. Fair surgical outcome was defined as single operation but fair cosmesis (residual ptosis between 2 and $3 \mathrm{~mm}$ ). Poor outcome was defined as more than one operation and poor cosmesis (residual ptosis more than $4 \mathrm{~mm}$ or equal to $4 \mathrm{~mm}$ ) with complications. Surgical success was defined as good surgical outcomes [Figure 1]. Surgical failure was defined as fair and poor surgical outcomes. Patients without a minimal follow-up after 6 months were excluded.

\section{Statistical methods}

The patients were classified according to the two outcomes, success or failure, either with respect to vision or surgery. Study variables included demographic data, operation data, refractive data, complications, and visual outcome status. The analysis was multivariate using non-parametric statistical methods. Two-group comparisons were made with the Mann-Whitney U test and three-group comparisons were made with the KruskalWallis test for continuous variables. Furthermore, Fisher's exact test was used for the categorical variables. Values of $p<0.05$ were considered statistically significant. The objective of the study was to identify predictors for the visual and surgical outcomes. 


\section{RESULTS}

From 1991 through 2000, 84 children consecutively met the inclusion criteria for this study. Fifty-three (63.1\%) patients were boys and $31(36.9 \%)$ patients were girls. The clinical characteristics of these 84 patients are listed in Table 1. The database identified $31(36.9 \%)$ patients with severe ptosis, $41(48.8 \%)$ with moderate ptosis, and $12(14.3 \%)$ patients with mild ptosis. Patient age at surgery ranged from 11 months to 7 years 9 months (mean $\pm \mathrm{SD}, 38.9 \pm 22.3$ months). The median patient age was 2 years 10 months. The minimum postoperative observation period was 6 months, and the maximum postoperative follow-up was 195 months (mean, 77.6 months).

According to the postoperative refractive data and visual status, amblyogenic ametropia was found in $27 \mathrm{pa}-$ tients $(32.1 \%, 27 / 84), 21(77.8 \%)$ of whom were found to

Table 1: Clinical characteristics of 84 patients who underwent levator resection for unilateral congenital blepharoptosis

\begin{tabular}{|c|c|}
\hline Unilateral ptosis $(N=84)$ & No. of patients $(\%)$ \\
\hline \multicolumn{2}{|l|}{ Sex } \\
\hline Male & $53(63.1)$ \\
\hline Female & $31(36.9)$ \\
\hline \multicolumn{2}{|l|}{ Involved eye } \\
\hline Right & $45(53.6)$ \\
\hline Left & $39(46.4)$ \\
\hline \multicolumn{2}{|l|}{ Severity } \\
\hline Mild & $12(14.3)$ \\
\hline Moderate & $41(48.8)$ \\
\hline Severe & $31(36.9)$ \\
\hline \multicolumn{2}{|l|}{ OP age of patient } \\
\hline$<2$ years & $31(36.9)$ \\
\hline $2-5$ years & $36(42.9)$ \\
\hline 5-8 years & $17(20.2)$ \\
\hline \multicolumn{2}{|l|}{ Combined } \\
\hline Amblyogenic ametropia & $27(32.1)$ \\
\hline Anisometropia & $41(48.8)$ \\
\hline \multicolumn{2}{|l|}{ BCVA } \\
\hline Amblyopia (BCVA<0.7) & $14(16.7)$ \\
\hline No amblyopia (BCVA>0.7) & $70(83.3)$ \\
\hline Complications & $13(15.5)$ \\
\hline Follow-up done after (Ms) & $77.6(6-195) 75.5$ \\
\hline
\end{tabular}

Abbreviations: BCVA: Best-corrected visual acuity; Ms: Months have astigmatism greater than 2.50 diopters of cylinder, 2 were found to have myopia greater than 3.0 diopters, 2 were found to have hyperopia greater than 4.5 diopters, and 2 were found to have compound astigmatism (with a spherical equivalent greater than 8 diopters). Anisometropia was found in 41 patients $(48.8 \% ; 41 / 84), 34(82.9 \%)$ of whom were found to have astigmatism differences of greater than 1.00 diopter of cylinder between the two eyes. Fourteen (16.7\%) patients ( 8 males and 6 females) were found to have amblyopia (best-corrected visual acuity of 0.7 or less) [Table 2]. If the non-operated eye was used as a control, $9(10.7 \%)$ patients were found to have amblyopia (greater than 2 Snellen lines difference from the non-operated eye) (cases 1-9). Three patients $(3.6 \%)$ had amblyopia in the non-operated eye. The reasons for amblyopia included refractive errors (11 cases), decreased vision by corneal scarring ( 2 cases), and stimulus deprivation by ptosis ( 1 case). Of the two patients with corneal scarring, one (Case 4) [Table 2] developed severe lagopthalmos and entropion in the operated eye after surgery. The patients received corrective surgery for entropion 1 month after levator resection. However, the ultimate visual acuity of the operated eye was 0.1 . The other patients (Case 7) [Table 2] developed lagopthalmos and persistent corneal epithelial defects in the operated eye, and then the operated eye had corneal opacity and decreased vision. Two patients developed astigmatism in the operated eye (cases 2 and 9) [Table 2] and their eyes developed amblyopia after surgery because of irregular follow-up.

Of the 31 patients with severe ptosis, 14 (45.2\%) patients underwent surgery at the age of 2 years or less, $14(45.2 \%)$ patients underwent surgery at ages between 2 and 5 years (including 5 years), and $3(9.6 \%)$ patients underwent surgery at ages between 5 and 8 years (including 8 years). Of the 12 patients with mild ptosis, no patient underwent surgery at an age of 2 years or less, $8(66.7 \%)$ patients underwent surgery at ages between 2 and 5 years (including 5 years), and $4(33.3 \%)$ patients underwent surgery at ages between 5 and 8 years (including 8 years).

\section{Amblyopia and non-amblyopia}

There were no significant differences in gen$\operatorname{der}(p=0.7627)$, laterality $(p=0.7784)$, preoperative severity of ptosis $(p=1.00)$, anisometropia $(p=0.2496)$, and the
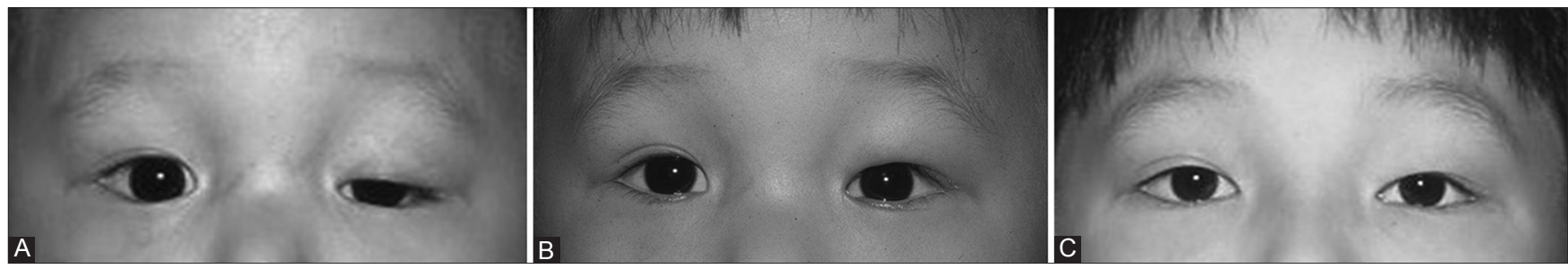

Figure 1: (A) Preoperative photo of a boy of age 1 year 10 months with left congenital severe ptosis. (B) Same patient's appearance 1 week after levator resection, undergoing levator resection at the age of 2 years 9 months. (C) Same patient's appearance 8 years after levator resection. 
Table 2: General information for 14 patients with amblyopia following unilateral levator resection

\begin{tabular}{|c|c|c|c|c|c|c|c|c|}
\hline \multirow{2}{*}{$\begin{array}{l}\text { No/ } \\
\operatorname{sex}\end{array}$} & \multirow{2}{*}{$\begin{array}{l}\text { Severity } \\
\text { of ptosis }\end{array}$} & \multirow{2}{*}{$\begin{array}{c}\text { Age } \\
\text { at OP } \\
\text { (months) }\end{array}$} & \multirow{2}{*}{$\begin{array}{l}\text { Age at } \\
\text { last visit } \\
\text { (months) }\end{array}$} & \multicolumn{2}{|c|}{ Preoperative refraction } & \multicolumn{2}{|c|}{ Postoperative refraction } & \multirow{2}{*}{$\begin{array}{l}\text { Amblyopia } \\
\text { reasons }\end{array}$} \\
\hline & & & & Operated eye & Non-operated eye & Operated eye & Non-operated eye & \\
\hline $1 / \mathrm{M}$ & Mo & 67 & 92 & $\begin{array}{c}0.1 \\
(0.4 \times+1.75 /-2.0 \times 140)\end{array}$ & $\begin{array}{c}0.4 \\
(0.9 \times+0.50 /-1.0 \times 20)\end{array}$ & $\begin{array}{c}0.1 \\
(0.7 \times+1.0 /-3.00 \times 150)\end{array}$ & $\begin{array}{c}0.7 \\
(1.0 \times 0 /-1.00 \times 30)\end{array}$ & AI, HAs \\
\hline $2 / \mathrm{M}$ & Mo & 61 & 137 & $\begin{array}{c}0.4 \\
(0.7 \times 0 /-1.25 \times 20)\end{array}$ & $\begin{array}{c}0.4 \\
(0.8 \times 0 /-1.25 \times 155)\end{array}$ & $\begin{array}{c}0.1 \\
(0.7 \times-2.25 /-2.75 \times 170)\end{array}$ & $\begin{array}{c}0.06 \\
(1.0 \times-3.75)\end{array}$ & AI, HAs \\
\hline $3 / \mathrm{M}$ & $S$ & 15 & 110 & & & $\begin{array}{c}0.1 \\
(0.6 \times+2.00 /-2.75 \times 175)\end{array}$ & $\begin{array}{c}0.5 \\
(1.0 \times+1.50 /-1.25 \times 170)\end{array}$ & AI, HAs \\
\hline $4 / F$ & $\mathrm{~S}$ & 12 & 92 & & & $\begin{array}{c}0.03 \\
(0.1 \times+3.00 /-5.00 \times 25)\end{array}$ & $\begin{array}{c}0.5 \\
(0.8 \times+0.75 /-2.75 \times 175)\end{array}$ & $\begin{array}{l}\text { CS, AI, } \\
\text { HAs }\end{array}$ \\
\hline $5 / \mathrm{M}$ & Mo & 35 & 160 & & & $\begin{array}{c}0.5 \\
(0.7 \times+3.50 /-1.50 \times 150)\end{array}$ & $\begin{array}{c}0.1 \\
(1.0 \times-1.75)\end{array}$ & $\mathrm{AI}$ \\
\hline $6 / \mathrm{M}$ & Mo & 13 & 149 & & & $\begin{array}{c}0.03 \\
(0.7 \times+5.25 /-1.25 \times 165)\end{array}$ & $\begin{array}{c}0.6 \\
(1.0 \times+1.25 /-0.50 \times 160)\end{array}$ & AI, HH \\
\hline $7 / \mathrm{F}$ & Mo & 74 & 103 & $\begin{array}{c}0.05 \\
(0.8 \times-2.25 /-1.50 \times 30)\end{array}$ & $\begin{array}{c}0.06 \\
(1.0 \times-2.25 /-1.00 \times 0)\end{array}$ & $\begin{array}{c}0.07 \\
(0.6 \times-2.75 /-1.75 \times 0)\end{array}$ & $\begin{array}{c}0.05 \\
(1.0 \times-3.25 /-1.00 \times 0)\end{array}$ & $\mathrm{CS}$ \\
\hline $8 / \mathrm{M}$ & S & 26 & 221 & & & $\begin{array}{c}0.5 \\
(0.7 \times+1.00 /-1.50 \times 130)\end{array}$ & $\begin{array}{c}0.04 \\
(1.0 \times-4.50)\end{array}$ & AI \\
\hline 9/M & $\mathrm{Mi}$ & 85 & 91 & $\begin{array}{c}0.2 \\
(0.8 \times+1.25 /-3.25 \times 180)\end{array}$ & $\begin{array}{c}0.5 \\
(1.0 \times+1.25 /-1.25 \times 10)\end{array}$ & $\begin{array}{c}0.2 \\
(0.7 \times 0 /-4.50 \times 180)\end{array}$ & $\begin{array}{c}0.5 \\
(1.0 \times 0 /-1.00 \times 170)\end{array}$ & AI, HAs \\
\hline $10 / \mathrm{M}$ & $\mathrm{Mi}$ & 62 & 126 & $\begin{array}{c}0.1(\mathrm{NC}) \\
(-6.50 /-1.75 \times 170)\end{array}$ & $\begin{array}{c}0.3 \\
(0.6 \times-1.00)\end{array}$ & $\begin{array}{c}0.01 \\
(0.7 \times-6.75 /-1.25 \times 165)\end{array}$ & $\begin{array}{c}0.2 \\
(0.8 \times-2.75 /-1.25 \times 10)\end{array}$ & AI, HM \\
\hline $11 / \mathrm{M}$ & $\mathrm{S}$ & 83 & 90 & $0.5 \times-0.50 /-2.50 \times 0$ & $0.8 \times 0 /-2.00 \times 85$ & $\begin{array}{c}0.5 \\
(0.7 \times+0.25 /-3.00 \times 180)\end{array}$ & $\begin{array}{c}0.5 \\
(0.9 \times 0 /-2.50 \times 170)\end{array}$ & $\mathrm{SD}, \mathrm{HAs}$ \\
\hline $12 / \mathrm{M}$ & Mo & 24 & 87 & & & $\begin{array}{c}0.4 \\
(0.6 \times 0 /-3.50 \times 175)\end{array}$ & $\begin{array}{c}0.4 \\
(0.6 \times 0 /-3.50 \times 175)\end{array}$ & HAs \\
\hline $13 / \mathrm{F}$ & S & 76 & 180 & $\begin{array}{c}0.02 \\
(0.3 \times+8.5 /-3.0 \times 20)\end{array}$ & $\begin{array}{c}0.02 \\
(0.6 \times+8.0 /-1.75 \times 160)\end{array}$ & $\begin{array}{c}0.2 \\
(0.5 \times+7.00 /-3.00 \times 15)\end{array}$ & $\begin{array}{c}0.5 \\
(0.7 \times+6.25 /-2.50 \times 155)\end{array}$ & HA \\
\hline $14 / \mathrm{F}$ & Mo & 12 & 69 & & & $\begin{array}{c}0.03 \\
(0.1 \times+8.50)\end{array}$ & $\begin{array}{c}0.2 \\
(0.3 \times+7.00 /-1.00 \times 140)\end{array}$ & $\mathrm{HH}$ \\
\hline
\end{tabular}

Abbreviations: S: Severe; Mo: Moderate; Mi: Mild; AI: Anisometropia; HAs: High astigmatism; CS: Corneal scarring; HM: High myopia; SD: Stimulus deprivation; HH: High hyperopia

follow-up periods ( $p=0.6788$ ) between the amblyopia and non-amblyopia groups, except in the time (age) of the surgery $(p=0.0058)$ and amblyogenic ametropia $(p=0.0001)$. Furthermore, the age at which surgery was done was divided into two groups: 5 years or less, and over 5 years to 8 years. The patients on whom surgery was done at ages of over 5 years had a higher amblyopia rate [OR: 0.1717 (0.0406-0.7049), $p=0.0062]$. However, the patients who had the surgery done at 2 years of age or less did not have significantly better outcomes compared to those who were operated on when they were between 2 and 5 years old [OR: 3.213 (0.479-36.326), $p=0.2356$ ].

Compared with the amblyopia group, the non-amblyopia group had a significantly lower percentage of amblyogenic ametropia. Comparison of the characteristics of patients with amblyopia and non-amblyopia is given in Table 3.

\section{Surgical success and failure}

Eighty-one of 84 (96.4\%) patients had the condition corrected with a single surgery. Re-operations were required in the case of three eyelids. The details of the patients with complications are listed in Table 4. One patient (Case 12) [Table 4] had a cosmetically unacceptable high lid position postoperatively and required revision surgery on the second day after the operation. Two patients (cases 1 and 5) [Table 4] with the upper eyelid $3 \mathrm{~mm}$ below the superior limbus had repeated surgery, with the period between the first and second surgeries being 40 months and 84 months, respectively. Nocturnal lagophthalmos and superficial punctuate erosion were the most common complications after levator resection. In addition, two patients (cases 10 and 13) [Table 4] required long-term lubricants for constant superficial punctuate erosion. Two patients (cases 9 and 11) [Table 4] had severe exposure keratopathy that resulted in corneal scarring and decreased vision after surgery. There were seven patients with poor surgical outcomes. In the case of six eyelids, the results were fair but no further surgeries were carried out. As a result, 71 of $84(84.5 \%)$ patients had good surgical outcomes (surgical success).

There was no significant difference in gender $(P=0.2151)$, laterality $(p=0.5632)$, visual outcomes $(p=0.4473)$, and 
follow-up period ( $p=0.7152$ ) between the surgical success and failure groups. Furthermore, the cases were divided into two age groups depending on the age at which the surgery was done: 2 years or less, and over 2 years up to 8 years. It was found that severe ptosis $(p=0.0288)$ and surgery done under 2 years of age $(p=0.0126)$ have higher risks of surgical failure [Table 5].

Of the 13 eyelids with surgical failure, $9(69 \%)$ eyelids had severe ptosis and $4(31 \%)$ eyelids had moderate ptosis. Of the 31 eyelids with severe ptosis, $22(71 \%)$ eyelids had surgical success. All the eyelids with mild ptosis had surgical success. The two eyelids on which a second surgery was done for under-correction were severe ptosis cases and underwent levator resection at the age of 1 year and 1 year 4 months. All of the six eyelids with fair surgical results had severe ptosis.

Of the 13 patients with surgical failure, $9(69 \%)$ patients underwent surgical correction at an age of 2 years or less. In the group having surgery at 2 years or less, $29 \%(9 / 31)$ of

Table 3: Comparison of patient characteristics between the amblyopia group and non-amblyopia group following unilateral levator resection

\begin{tabular}{|c|c|c|c|}
\hline & $\begin{array}{c}\text { No amblyopia } \\
(\text { BCVA >0.7) } \\
\quad(n=70)\end{array}$ & $\begin{array}{c}\text { Amblyopia } \\
(\mathrm{BCVA}<0.7) \\
(n=14)\end{array}$ & $p$ value \\
\hline \multicolumn{4}{|l|}{ Sex } \\
\hline Male & 45 & 8 & 0.7627 \\
\hline Female & 25 & 6 & \\
\hline \multicolumn{4}{|l|}{ Involved eye } \\
\hline Right & 38 & 7 & 0.7784 \\
\hline Left & 32 & 7 & \\
\hline \multicolumn{4}{|l|}{ Severity } \\
\hline Mild & 10 & 2 & 1.00 \\
\hline Moderate & 34 & 7 & \\
\hline Severe & 26 & 5 & \\
\hline \multicolumn{4}{|l|}{ Age of surgery } \\
\hline$<2$ years & 26 & 5 & $0.0058 * *$ \\
\hline $\begin{array}{l}2-5 \text { years } \\
\text { (include } 5 \text { years) }\end{array}$ & 34 & 2 & \\
\hline $\begin{array}{l}5-8 \text { years } \\
\text { (include } 8 \text { years) }\end{array}$ & 10 & 7 & \\
\hline$<5$ years & 60 & 7 & $0.0062 * *$ \\
\hline $\begin{array}{l}5-8 \text { years } \\
\text { (include } 8 \text { years) }\end{array}$ & 10 & 7 & \\
\hline \multicolumn{4}{|l|}{ Refractive status } \\
\hline Ametropia & 16 & 11 & $0.0001 * *$ \\
\hline Non-ametropia & 54 & 3 & \\
\hline Anisometropia & 32 & 9 & 0.2496 \\
\hline Non-anisometropia & 38 & 5 & \\
\hline F-U done after (Ms) & $(78.1 \pm 39.8), 77$ & $(75.1 \pm 53.8), 70$ & 0.6788 \\
\hline
\end{tabular}

patients had poor or fair surgical results. By comparison, for the group having surgery at ages over 2 years, $7.5 \%(4 / 53)$ of the patients had failed surgical outcomes. Of the six patients with fair surgical outcomes, two were due to lateral ptosis [Figure 2] and four patients were due to residual ptosis $2 \mathrm{~mm}$. The two patients with lateral ptosis underwent surgery at the age of less than 2 years.

\section{DISCUSSION}

The majority of pediatric blepharoptosis cases were attributable to simple congenital ptosis, ${ }^{[9,11,26,27]}$ and 70-80\% of those are unilateral. ${ }^{[2,4,6,7,27-29]}$ Eyes with congenital unilateral blepharoptosis were more predisposed to develop amblyopia. The incidence of amblyopia in the patients with congenital unilateral ptosis preoperatively ranged from $27 \%$ to $75 \% .{ }^{[30-32]}$ Surgical correction may be indicated whenever stimulus deprivation amblyopia due to covered optical axis develops.

In 1993, Holds et al., adopted the Whitnall sling with superior tarsectomy for the correction of severe unilateral blepharoptosis, achieving good surgical results in $17(68 \%)$ of their 25 patients. ${ }^{[33]}$ Cates and Tyers also reported $78 \%$ successful outcomes at 6 weeks following surgery in all unilateral cases of anterior levator resection, with the success falling slightly to $74 \%$ by 6 months. ${ }^{[29]}$ In this study, $84.5 \%$ of the patients had good surgical results following levator resection and $96.4 \%$ of patients were corrected with a single surgery.

\section{Factors affecting surgical outcome}

Similar to previous studies, ${ }^{[9,26,28]} 63 \%$ of the patients were males, even though this study focused on patients with unilateral blepharoptosis and excluded the patients with strabismus. Nevertheless, patient gender, laterality, postoperative visual outcomes, and follow-up periods appeared to have no significant effect on the postoperative surgical success. Severity $(p=0.0288)$ and surgery at less than 2 years of age $(p=0.0126)$ were the important factors

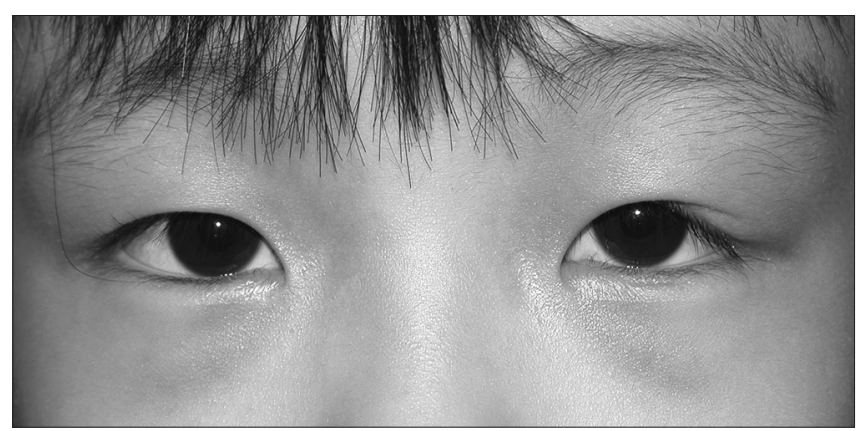

Figure 2: Postoperative photo of a girl of age 5 years 5 months with left lateral ptosis [patient 3 in Table 4], undergoing levator resection at the age of 1 year. 
Table 4: General information on 13 patients with surgical failure after unilateral levator resection

\begin{tabular}{|c|c|c|c|c|c|c|}
\hline No/sex & Severity of ptosis & Age at OP (months) & Age at last visit (months) & Surgical outcomes & Complications & BCVA \\
\hline $1 / \mathrm{M}$ & $S$ & 12 & 111 & $\mathrm{P}$ & Reop (under-correction) & 1.0 \\
\hline $2 / \mathrm{M}$ & $S$ & 38 & 111 & F & Mild ptosis & 1.0 \\
\hline $3 / \mathrm{F}$ & S & 12 & 65 & $\mathrm{~F}$ & Lateral ptosis & 1.0 \\
\hline $4 / F$ & S & 14 & 150 & $\mathrm{~F}$ & Lateral ptosis & 1.0 \\
\hline $5 / \mathrm{F}$ & S & 16 & 119 & $\mathrm{P}$ & Reop (under-correction) & 1.0 \\
\hline $6 / \mathrm{M}$ & S & 24 & 163 & $\mathrm{~F}$ & Mild ptosis & 1.0 \\
\hline $7 / \mathrm{F}$ & $S$ & 11 & 81 & F & Mild ptosis & 0.8 \\
\hline $8 / \mathrm{F}$ & S & 41 & 73 & $\mathrm{~F}$ & Mild ptosis & 0.9 \\
\hline $9 / \mathrm{F}$ & $\mathrm{S}$ & 12 & 92 & $\mathrm{P}$ & Corneal scarring & 0.1 \\
\hline $10 / \mathrm{M}$ & Mo & 24 & 87 & F & Lagophthalmos (SPK) & 0.6 \\
\hline $11 / \mathrm{F}$ & Mo & 74 & 103 & $\mathrm{P}$ & Corneal scarring & 0.6 \\
\hline $12 / \mathrm{M}$ & Mo & 36 & 128 & $\mathrm{P}$ & Reop (over-correction) & 1.0 \\
\hline $13 / \mathrm{M}$ & Mo & 22 & 92 & $\mathrm{~F}$ & Lagophthalmos (SPK) & 1.0 \\
\hline
\end{tabular}

Abbreviations: S: Severe; Mo: Moderate; P: Poor; F: Fair; SPK: Superficial punctuate keratopathy; Reop: Re-operation; BCVA: Best-corrected visual acuity

Table 5: Comparison of patient characteristics between the surgical success group and the surgical failure group after unilateral levator resection

\begin{tabular}{|c|c|c|c|}
\hline & $\begin{array}{c}\text { Surgical } \\
\text { success }(n=71)\end{array}$ & $\begin{array}{l}\text { Surgical failure } \\
\qquad(n=13)\end{array}$ & $p$ value \\
\hline \multicolumn{4}{|l|}{ Sex } \\
\hline Male & 47 & 6 & \multirow[t]{2}{*}{0.2151} \\
\hline Female & 24 & 7 & \\
\hline \multicolumn{4}{|l|}{ Involved eye } \\
\hline Right & 37 & 8 & \multirow[t]{2}{*}{0.5632} \\
\hline Left & 34 & 5 & \\
\hline \multicolumn{4}{|l|}{ Severity } \\
\hline Mild & 12) & 0 & \multirow[t]{3}{*}{$0.0288^{*}$} \\
\hline Moderate & 37 & 4 & \\
\hline Severe & 22 & 9 & \\
\hline \multicolumn{4}{|l|}{ Age at surgery } \\
\hline$<2$ years & 22 & 9 & \multirow[t]{2}{*}{$0.0426 *$} \\
\hline $\begin{array}{l}2-5 \text { years } \\
\text { (include } 5 \text { years) }\end{array}$ & 33 & 3 & \\
\hline $\begin{array}{l}5-8 \text { years } \\
\text { (include } 8 \text { years) }\end{array}$ & 16 & 1 & \\
\hline$<2$ years & 22 & 9 & $0.0126^{*}$ \\
\hline $2-8$ years & 49 & 4 & \\
\hline \multicolumn{4}{|l|}{ Visual status } \\
\hline No amblyopia & 60 & 10 & \multirow[t]{2}{*}{0.4473} \\
\hline Amblyopia & 11 & 3 & \\
\hline $\mathrm{F}-\mathrm{U}$ done $\operatorname{after}(\mathrm{Ms})$ & $(77.1 \pm 43.6), 75$ & $(80.7 \pm 33.8), 80$ & 0.7152 \\
\hline
\end{tabular}

*p<0.05; Two-group comparisons were made with the Mann-Whitney U test; Three-group comparisons were made with the Kruskal-Wallis test for continuous variables; Fisher's exact test was used for the categorical variables; Abbreviations: Ms: Months

contributing to the failure of the levator resection for the patients with unilateral congenital ptosis.

Frontalis suspension surgery is generally indicated when the levator muscle has poor function. ${ }^{[9-13]}$ Nevertheless, the ideal approach of the frontalis sling for unilateral blepharoptosis has to be establis hed and the ptosis recurrence rates after frontalis suspension are relatively high, ranging from $4 \%$ to $69 \%$ for different suture materials. ${ }^{[12,20,34]}$ Levator resection for congenital unilateral ptosis is currently advocated and yields satisfactory results. ${ }^{[18,29,35]}$ However, it is less successful in patients with severe ptosis and needs to adopt supra-maximum resection for the patients with poor levator function. ${ }^{[15-17,33,36]}$ Press and Hibner reported 82\% (36/44) of patients achieve a satisfactory eyelid elevation for unilateral congenital ptosis with poor levator function, ${ }^{[36]}$ whereas Epstein et al., reported $75 \%(6 / 8)^{[15]}$ and Holds et al., reported $68 \%(17 / 25) \cdot{ }^{[33]}$ In this study, $22(71 \%)$ patients with severe unilateral ptosis had successful surgical results.

Although maximal levator resection can achieve successful surgical results for patients with poor levator function, it risks problematic lagophthalmos after surgery. One eyelid (Case 9) [Table 4] with severe ptosis developed severe exposure keratopathy that resulted in decreased vision to 0.1 . The degree of postoperative lagophthalmos is associated with the amount of levator complex resection, the severity of the blepharoptosis, and poor levator muscle function. ${ }^{[37]}$ It is essential to educate the patients, or those caring for the patients, to provide precise care of the operated eye after surgery (including applying lubricant ointment and night patch) and follow-up the patients closely until the patients have adjusted to lagophthalmos.

In the present series, 29\% (9/31) of patients having surgery at 2 years or less had poor or fair results. When levator resection was performed at the age of more than 2 years, only $7.5 \%(4 / 53)$ of patients had failed surgical results. It is more challenging to perform levator resection at the age of 2 years or less. At such young age, there is a risk of developing lateral drop of the eyelid and under-correction after surgery because the palpebral fissure length is relatively short and 
the anatomic structures of the eyelid are crowded, with the lacrimal gland occupying the lateral space.

Palpebral fissure length rapidly grows from 29 weeks of gestation to 2 years of age, making it preferable to perform levator resection after the age of 2 years. ${ }^{[38]}$ Furthermore, the height of the palpebral fissure achieves $93.3 \%$ of development, and the binocular width achieves $86 \%$ at the age of 2 years. ${ }^{[39]}$ Full development of eyelids is nearly achieved after 2 years of age. In addition, the assessment of the ptosis can be more precise after the age of 2 years. Although it is generally advised that blepharoptosis surgery be delayed until the child is at least 3 years of age, the operation can take place as early as the age of 2 years if needed.

\section{Factors affecting visual outcomes}

This was a retrospective study in which the patients were part of a referral population. However, the distribution of the amount of ptosis is probably typical of patients with congenital blepharoptosis. Patients varied in age from 11 months to 7 years 9 months at the time of surgery. Some patients were too young to get precise cycloplegic refraction and visual acuities. Therefore, we focused on the postoperative refractive status and visual outcomes.

Of the 14 patients with postoperative amblyopia, in $11(78.6 \%)$ cases, the cause was amblyogenic ametropia and/or anisometropia. In two (cases 4 and 7) [Table 2] cases, the cause was corneal scarring after surgery. One eyelid (Case 11) [Table 2] with severe ptosis underwent levator resection at the age of 6 years 11 months and still had amblyopia after surgery. Although this case showed an increase in astigmatic error of $0.5 \mathrm{D}$ after surgery, it was assumed that the patient had stimulus deprivation amblyopia by ptosis due to the delayed surgery, as compared to the refractive status of the non-operated eye.

Amblyogenic ametropia was found in $27 \mathrm{pa}-$ tients $(32.1 \%), 21(77.8 \%)$ of whom were found to have astigmatism greater than 2.50 diopters of cylinder. The incidence of high astigmatism in this study was $25 \%$, which is similar to the incidence $(25.3 \%)$ reported by Kao and her coworkers. ${ }^{[28]}$ The incidence of anisometropia was $48.8 \%$, and $40.5 \%$ patients had astigmatic anisometropia. However, amblyogenic ametropia (especially high astigmatism) was the main reason for the cause of amblyopia. In the group of postoperative amblyopia, 11 (78.6\%) patients had amblyogenic ametropia and $9(64.3 \%)$ patients had anisometropia. Stark et al., also reported that ametropia was responsible for $34 \%$ and anisometropia for $28.3 \%$ of the amblyopia cases. ${ }^{[40]}$

Anderson and Baumgartner reported a 1.6\% incidence of preoperative diagnosis of amblyopia with no apparent cause other than the ptotic eyelid, ${ }^{[1]}$ whereas Harrad et al., reported a $2.3 \%$ incidence, ${ }^{[41]}$ Hornblass et al., reported $6 \%,{ }^{[42]}$ Dray et al., reported 6.9\%, ${ }^{[4]}$ Oral et al., reported
$12 \%,{ }^{[6]}$ and Lin et al., reported $16.7 \%$ incidence. ${ }^{[7]}$ Fiergang et al., reported that $71 \%$ of the patients with unilateral or asymmetric congenital blepharoptosis and a compensatory head posture had amblyopia, even in the absence of significant anisometropia and strabismus. ${ }^{[3]}$ As a result, several case series of severe congenital blepharoptosis adopted early correction in infants to prevent occlusion amblyopia and developing strabismus. ${ }^{[7,22,23]}$ Conversely, some authors advocated congenital blepharoptosis need not be corrected early in life because stimulus deprivation due to ptosis presents the least common cause of amblyopia. ${ }^{[2,32,40]}$ Some studies even found postoperative increased astigmatism in eyes that underwent levator resection for unilateral congenital blepharoptosis. ${ }^{[2,23]}$ Blepharoptosis surgery is usually recommended at ages between 3 and 5 years..$^{[2,9,24,43]}$

In the case series reported here, the patients operated on at 2 years of age or less did not have significantly better visual outcomes compared to those who were operated on between 2 and 5 years of age. In addition, there were higher surgical failure rates for patients with surgery at 2 years of age or less. Therefore, regarding the patients with severe unilateral congenital blepharoptosis, levator resection can be performed at the age of 2-3 years with the advantage of lower risk of surgical failure and occlusion amblyopia. The general tendency is for parents to want their children have surgery just before going to school at around the age of 5 years. Although it is rare to have occlusion amblyopia for patients with mild unilateral congenital blepharoptosis, it is possible to have amblyopia caused by amblyogenic ametropia. Patients with mild unilateral blepharoptosis who underwent levator resection at the age of 5 years were able to have any functional, cosmetic, or psychological disability rectified. However, it is important to follow postoperative cycloplegic refraction and visual status, no matter at what age the operation is done. There were two patients with their amblyopia becoming manifest after surgery in this study due to irregular follow-up.

\section{Conclusion}

The study limitations were its retrospective design and some patients were without complete preoperative refraction status. Despite the study limitations, the results suggest that levator resection was performed at an age between 2 and 5 years with better surgical outcome and was helpful in the treatment of amblyopia for unilateral congenital blepharoptosis without strabismus. However, only prospective randomized studies can give a more accurate conclusion in this regard. Amblyogenic ametropia is the leading cause of amblyopia in the patients with unilateral isolated congenital blepharoptosis. The results of this study indicate early examination and careful monitoring of the patient's refractive and visual status until visual maturity is obtained, even though the ptosis is corrected. 


\section{REFERENCES}

1. Anderson RL, Baumgartner SA. Amblyopia in ptosis. Arch Ophthalmol 1980;98:1068-9.

2. Merriam WW, Ellis FD, Helveston EM. Congenital blepharoptosis, anisometropia, and amblyopia. Am J Ophthalmol 1980;89:401-7.

3. Fiergang DL, Wright KW, Foster JA. Unilateral or asymmetric congenital ptosis, head posturing, and amblyopia. J Pediatr Ophthalmol Strabismus 1999;36:74-7.

4. Dray JP, Leibovitch I. Congenital ptosis and amblyopia: A retrospective study of 130 cases. J Pediatr Ophthalmol Strabismus 2002;39:222-5.

5. Gusek-Schneider GC, Martus P. Stimulus deprivation amblyopia in human congenital ptosis: A study of 100 patients. Strabismus 2000;8:261-70.

6. Oral Y, Ozgur OR, Akcay L, Ozbas M, Dogan OK. Congenital ptosis and Amblyopia. J Pediatr Ophthalmol Strabismus 2010;47:101-4.

7. Lin LK, Uzcategui N, Chang EL. Effect of surgical correction of congenital ptosis on amblyopia. Ophthal Plast Reconstr Surg 2008;24:434-6

8. Salinas GR, Centelles IA, Rondón IR, Sánchez Tde J, Salas SV, Oduardo MD. Improved visual acuity after frontalis sling surgery for simple congenital ptosis. MEDICC Rev 2011;13:23-8.

9. Lee V, Konrad H, Bunce C, Nelson C, Collin JRO. Aetiology and surgical treatment of childhood blepharoptosis. Br J Ophthalmol 2002;86:1282-6.

10. Fox SA. Congenital ptosis. II Frontalis sling. J Paediatr Ophthalmol 1966;3:25-8.

11. Finsterer J. Ptosis: Causes, presentation and management. Aesthetic Plastic Surg 2003;27:193-204.

12. Deenstra W, Melis P, Kon M, Werker P. Correction of severe blepharoptosis. Ann Plast Surg 1996;36:348-53.

13. Wilaon ME, Jonson RW. Congenital ptosis: Long-term results of treatment using lyophilized fascia lata for frontalis suspensions. Ophthalmology 1991;98:1234-7.

14. Whitehouse GM, Grigg J RB, Martin FJ. Congenital ptosis: Results of surgical management. Aust N Z J Ophthalmol 1995;23:309-14.

15. Epstein GA, Putterman AM. Super-maximum levator resection for severe unilateral congenital blepharoptosis. Ophthalmic Surg 1984;15:971-9.

16. Mauriello JA, Wagner RS, Caputo AR, Natale B, Lister M. Treatment of congenital ptosis by maximal levator resection. Ophthalmology 1986;93:466-9.

17. Anderson RL, Jordan DR, Dutton JJ. Whitnall's sling for poor function ptosis. Arch Ophthalmol 1990;108:1628-32.

18. Blomgren I, Holmstrom H. Anterior levator resection in congenital genuine blepharoptosis. A follow-up of 55 operated eyelids. Scand J Plast Reconstr Surg 1986;20:189-95.

19. O`donnell B, Codère F, Dortzbach R, Lucarelli M, Kersten R, Rosser P. Clinical controversy: Congenital unilateral and jaw-winking ptosis. Orbit 2006;25:11-7.

20. Kersten RC, Bernardini FP, Khouri L, Moin M, Roumeliotis AA, Kulwin DR. Unilateral frontalis sling for the surgical correction of unilateral poor-function ptosis. Ophthal Plast Reconstr Surg $2005 ; 21: 412-7$

21. Deenstra W, Melis P, Kon M, Werker P. Correction of severe blepharoptosis. Ann Plast Surg 1996; 36:348-53.

22. Chong KK, Fan DS, Lai CH, Rao SK, Lam PT, Lam DS. Unilateral ptosis correction with mersilene mesh frontalis sling in infants: Thirteen-year follow-up report. Eye 2010;24:44-9.

23. Klimek DL, Summers CG, Letson RD, Davitt BV. Change in refractive error after unilateral levator resection for congenital ptosis. J AAPOS 2001;5:297-300.

24. Kumar S, Chaudhuri Z, Chauhan D. Clinical evaluation of refractive changes following brow suspension surgery in pediatric patients with congenital blepharoptosis. Ophthalmic Surg Lasers Imaging $2005 ; 36: 217-27$

25. Freuh HR. The mechanistic classification of ptosis. Ophthalmology 1980;87:1019-21.

26. Berry-Brincat A, Willshaw H. Paediatric blepharoptosis: A 10-year review. Eye 2009;23,1554-9.

27. Gusek-Schneider GC. Congenital ptosis: Amblyogenic refractive errors, amblyopia, manifest strabismus and stereopsis related to the types of ptosis. Data on 77 patients and review of the literature. Klin Monatsbl Augenheilkd 2002;219:340-8.

28. Kao SC, Tasi CC, Lee SM, Liu JH. Astigmatic change following congenital ptosis surgery. Chin Med J (Taipei) 1998;61:689-93.

29. Cates CA, Tyers AG. Outcomes of anterior levator resection in congenital blepharoptosis. Eye 2001;15:700-3.

30. Beneish R, William F, Polomeno RC, Little JM, Ramsey B. Unilateral congenital ptosis and amblyopia. Can J Ophthalmol 1983;18:127-30.

31. Klimek DL, Summers GC, Letson RD, Davitt BV. Change in refractive error after unilateral levator resection for congenital ptosis. J AAPOS 2001;5:297-300.

32. Gusek-Schneider GC, Martus P. Stimulus deprivation amblyopia in human congenital ptosis: A study of 100 patients. Strabismus 2000;8:261-70.

33. Holds JB, McLeish WM, Anderson RL. Whitnall's sling with superior tarsectomy for the correction of severe unilateral blepharoptosis. Arch Ophthalmol 1993;111:1285-91.

34. Ben Simon GJ, Macedo AA, Schwarcz RM, Wang DY, McCann JD, Goldberg RA. Frontalis suspension for upper eyelid ptosis: Evaluation of different surgical designs and suture material. Am J Ophthalmol 2005;140:877-85.

35. Whitehouse GM, Grigg JR, Martin FJ. Congenital ptosis: Results of surgical management. Aust N Z J Ophthalmol 1995;23:309-14.

36. Press UP, Hübner H. Maximal levator resection in the treatment of unilateral congenital ptosis with poor levator function. Orbit 2001;20:125-9.

37. Iljin A, Loba A, Omulecki W, Zielin ski A. Congenital blepharoptosis: Part I. Evaluation of the results of surgical treatment for congenital blepharoptosis. Acta Chir Plast 2003;45:8-12.

38. Thomas IT, Gaitantzis YA, Frias JL. Palpebral fissure length from 29 weeks gestation to 14 years. J Pediatr 1987;111:267-8.

39. Hreczko T, Farkas LG, Katic M. Clinical significance of age-related changes of the palpebral fissures between age 2 and 18 years in healthy Caucasians. Acta Chir Plast 1990;32:194-204. 
40. Stark N, Zubcov AA, Kast E, Gutermuth D. Amblyopia, refractive errors and strabismus in congenital ptosis. Ophthalmologe 1996;93:345-50.

41. Harrad RH, Graham CM, Collin JR. Amblyopia and strabismus in congenital ptosis. Eye 1988;2:625-7.
42. Hornblass A, Kass LG, Ziffer AJ. Amblyopia in congenital ptosis. Ophthalmic Surg 1995;26:334-7.

43. Harvey DJ, Iamphongsai S, Gosain AK. Unilateral congenital blepharoptosis repair by anterior levator advancement and resection: An educational review. Plast Reconstr Surg 2010;126:1325-31. 